\title{
The information system of learning quality control in higher education institutions: achievements and problems of European universities
}

\author{
Elena Orekhova ${ }^{1, *}$ and Nadezhda Shaidenko ${ }^{2}$ \\ ${ }^{1}$ ICFES RAE, 105062, Moscow, Russia \\ ${ }^{2}$ Federal Assembly of the RF, 103265, Moscow, Russia
}

\begin{abstract}
The article deals with the main trends in the development of the system of learning quality control connected with the European integration of higher education and the democratization of education. The authors analyze the state of information systems of learning quality control existing in European higher education and identify their strong and weak points. The authors show that in the learning process universities actively use innovative analytic methods as well as modern means of collecting, storing and transferring information that ensure the successful management of such a complex object as the university of the $21^{\text {st }}$ century.
\end{abstract}

The modern stage of education development is characterized by broadening contacts between the educational systems of different countries and regions of the world, striving for cooperation in the field of education and fruitful use of best international experience. The most important trends in education development are closely connected with the issue of the building of the assessment system that meet European standards and is based on modern technologies. The investigations show that assessment procedures and tools developed with traditional quantitative methods and sets of criteria do not considerably raise the quality of learning and even don't enable to sufficiently control it. Given the scale of the internationalization of education more attention is paid to the development of the mechanisms for effective accumulation, analysis and distribution of information that is vital for the universities and relevant to the needs of different user categories. These mechanisms should enable the wide use of modern information and communication technologies in external and internal quality control that make possible a rapid collection and transfer of information over any distance. [1]

Researchers suggest the use of ICT in education quality control with a technological revolution and emphasize that their interactivity, flexibility, capacity and integration ability give the opportunity to overcome the rigidity of control procedures as well as the limitations of time and space. Through the development of high-speed satellite communications and fiber-optic lines web technologies give access to a practically unlimited number of information sources. Nevertheless the dissemination of the practices of ICT use in learning quality control is restrained by national differences in the structural organization of the universities and in the institutional assessment procedures. European higher education institutions are characterized by diverse management systems and various criteria of quality assurance that hardly can be unified within a common regulated quality control framework. In this situation the system of key competences becomes an effective mechanism that enables the development of information systems of leaning quality control. These competences can be seen as subjects to control both from the viewpoint of the quality assurance process and learning outcomes. The transition to competence approach in quality control requires the module curriculum design, the introduction of credit and rating assessment systems. The main tools of quality assurance are the procedures of external and internal control with the use of accessible, effective and independent resources [2].

In the context of introducing information systems of learning quality control educational institutions should also consider the question of their economic efficiency. They can benefit from a modern information control for it requires fewer teachers but can involve more students. Therefore the studentacademic staff ratio index can be decreased. Thus, informatization enables to maximize control in education, i.e. to increase its "quantity" (the extent to which it is available) on one hand, and on the other hand, to raise its quality [3].

The practice of the organization of quality control systems in European universities shows that there exist the following types of interaction between the participants of control: student-to-student, student-toteacher, student-to-administration, and teacher-toadministration. Thereby, higher education learning theories developed the concept of activity structure connected with the successful design and use of computer applications in education, i.e. the activity model of the participants of educational process on the 
web. The typology of activity structures includes interpersonal activity (e.g. informational tutorship), operational activity (e.g. computer-based testing), and analytical activity (database creation) [4].

The use of information and communication technologies for learning quality control contributes to demonopolization of information sources as ICT help overcome the limitations of time and adapt the educational process to individual students' learning styles. This issue was discussed at the World Conference on Educational Multimedia that emphasized the need of the development of various control methods in education [5].

It's important to mention that nowadays students treat computers in an absolutely different way in comparison to their teachers many of whom are over fifty. Today's students tend to learn through visual images, they need visual incentives more often than previous generations. In some research we find the definition of a computer as a "child's machine" which is used for play, entertainment and learning. From the viewpoint of didactics the informatization of control increases the level of students' intellectual autonomy that directly contributes to strengthening their motivation and self-confidence. This tendency is mainly noted in the situations when students use ICT for self-control and therefore are able to manage their learning process.

The development of ICT competences in modern digital environment transforms the attitude to information control system. Now it is seen not only as the means of learning outcomes assessment but also as a cognitive tool that develops the abilities of human intelligence. This aspect of ICT usage is described in scientific literature with the term 'Mindtool'. So information control as a Mindtool means an intellectual partnership between a human and a computer built for the access to information and its interpretation as well as for the organization of knowledge. In this context M. Connell says that due to its technology oriented nature AI (artificial intelligence) is less suitable for a learning process and its control in comparison to IA (intelligence amplification) where technologies are subordinated to learning purposes [6].

The information environment also affects teacher's functions whose role transforms from being the only source of information, pedagogical influence and control in conventional instruction to a guide in digital knowledge systems and a control procedures designer. But despite the positive experience and significant achievements gained by European universities in the introduction of modern ICT methods of learning quality control many researchers and practitioners of university education admit that the ICT use for control in education is connected with a range of problems.

One of the most common disadvantages of quality control information systems is a network imperfection that impedes the work with data of any kind including transmission, gaining and processing. With the growth of information volume in the Internet the requests for information from databases face the universal technical limitations typical for networks, first of all the limited transmission capacity of data delivery channels. The users of these systems encounter similar difficulties with the navigation as the insufficient functionality of some on-line resources designed for learning control and self-control complicates the information search and the access to databases.

Another problem closely connected with the digital control methods is the problem of "cognitive overload". That means that the users should spend an unreasonable amount of time studying the control system functions in order to make the passing of control procedures comfortable both technologically and psychologically. Therefore cognitive overload becomes a negative consequence of information redundancy typical for the modern stage of ICT development. In addition to a great number and variety of information resources the interfaces of some databases also prepare difficulties for inexperienced users who lack appropriate computer skills. The learning of these control systems is time-consuming as many information resources don't contain user selflearning subsystems.

The content of information resources designed for learning quality control is characterized by nonuniformity of published materials. So they contain a significant number of statistical reports but not so many analytical reviews. The accessibility of user feedback which is considered the main advantage of information systems of learning quality control is not implemented to the full extent.

There also exist the problems of administration and regulations in the sphere of the use of information systems for learning quality control in higher education. The institutions have to adapt traditional control procedures prescribed by curricula, programs, charters and other documents that regulate university activity to the specific character of information control systems including learning outcomes validation. Administrative problems include as well database protection often connected with ethical aspects of communication in digital environment. Many European researchers pay special attention to the issue of sociocultural component of ICT use in education as the transcultural nature of networks, the domination (prevalence) of the English language and genetic ties with scientific community of North America became in the opinion of Europeans a serious test of cultural identity for many peoples.

European higher education face specific challenges associated with the transformation of teacher's role in information environment where there exist potential risks of dehumanization of education and elimination of a key process - personal interaction between academic staff and students in the classroom. Indeed, the maintenance of the balance between high-tech education and the education with a high contact level (also referred as "high-touch" education) requires real teachers to provide live contacts in digital society. Human sympathy and the ability to analyze students' personal characteristics still remain the responsibility of a teacher. [7]

Thus it's possible to draw a conclusion that despite the problems information systems of learning quality control have become widespread and popular in Europe. The specific character of its usage in European universities reflects the dynamics and 
autonomy of the modern digital systems developed for education quality assessment. Information and communication technologies enable to make information required for learning quality control relevant, accessible, timely and continuing. European integration and democratization of education contributes to the strengthening internal self-assessment in universities, the introduction of independent audit and effective management based on the wide use of information and communication technologies. The systematic organization of information control of learning quality can be seen as a growing trend of higher education development in the context of modern educational reforms.

\section{References}

1. T. Holm, and R. Sorup, Quality Procedures in European Higher Education (ENQA Occasional Papers, Section 2, 2003).

2. European Commission. Tuning Educational Structures in Europe: Final Report, Phase One, (Bilbao, 2003).
3. M.G. Moore. Distance Education: A Systems View (2nd Edition Paperback, 2005).

4. R. Halverson, and A. Smith, J. CTE, 26, (2010)

5. R. Ommerborn, and R. Schuemer, Behinderung und Fernstudium Eine Bestandsaufnahme (ZIFF, FernUniversität, Hagen 2006).

6. M.L. Connell, Computers in the Schools, 143-171 (2001).

7. D. Benyon, Experience with developing multimedia courseware for the World Wide Web: the need for better tools and clear pedagogy Available online: URL http://www.hbuk.co.uk/ap/ijhcs/webusability.html (accessed on 23.03.2016). 